\title{
REVIEW
}

\section{A Framework for Integrating Biosimilars Into the Didactic Core Requirements of a Doctor of Pharmacy Curriculum}

\author{
Edward Li, PharmD, MPH, ${ }^{\mathrm{a}}$ Jennifer Liu, PhD, ${ }^{\mathrm{b}}$ Monica Ramchandani, $\mathrm{PhD}^{\mathrm{b}}$ \\ ${ }^{\text {a }}$ University of New England College of Pharmacy, Portland, Maine \\ ${ }^{\mathrm{b}}$ Amgen Inc., Thousand Oaks, California \\ Submitted September 30, 2015; accepted December 13, 2016; published April 2017.
}

\begin{abstract}
Biologic drugs approved via the abbreviated United States biosimilar approval pathway are anticipated to improve access to medications by addressing increasing health care expenditures. Surveys of health care practitioners indicate that there is inadequate knowledge and understanding about biosimilars; this must be addressed to ensure safe and effective use of this new category of products. Concepts of biosimilar development, manufacturing, regulation, naming, formulary, and inventory considerations, as well as patient and provider education should be included within the doctor of pharmacy (PharmD) curriculum as preparation for clinical practice. Based on these considerations, we propose that PharmD graduates be required to have knowledge in the following domains regarding biologics and biosimilars: legal definition, development and regulation, state pharmacy practice laws, and pharmacy practice management. We link these general biosimilar concepts to the Accreditation Council for Pharmacy Education (ACPE) Standards 2016 and Center for the Advancement of Pharmacy Education (CAPE) Outcomes 2013, and provide example classroom learning objectives, in-class activities, and assessments to guide implementation.
\end{abstract}

Keywords: biosimilars, development, interchangeability, substitution, didactic requirements

\section{INTRODUCTION}

Pharmacy practice is evolving due to multiple factors, including the growth of health care expenditures in the United States, which is driven in part by increased spending on expensive new medications. ${ }^{1,2}$ Accordingly, the Pharmacy Forecast 2016-2020 recommends that hospitals and health systems should evaluate and expand their capabilities to manage these new specialty medications. ${ }^{3}$ Pharmacy curricula also must evolve to meet the demands of modern pharmacy practice. One major change has been the availability of biosimilars in the United States, a result of new legislation and loss of patent protection for many innovative biologics. There are four biosimilars that have been approved by the US Food and Drug Administration (FDA): Zarxio, a biosimilar for filgrastim, ${ }^{4}$ Inflectra, a biosimilar for infliximab, ${ }^{5}$ Erelzi, a biosimilar for etanercept, ${ }^{6}$ and AMJEVITA, a biosimilar for adalimumab. ${ }^{7}$ Thus, the Pharmacy Forecast advises that institutions "ensure that pharmacists are positioned to integrate biosimilars into the patient-care process" and recommends placing pharmacists at the nexus of interprofessional

Corresponding Author: Edward Li, University of New England College of Pharmacy, 716 Stevens Ave., Pharmacy Building 234, Portland, ME 04103. Tel: 207-221-4120.

E-mail: eli@une.edu collaboration and policy to support the appropriate use of biosimilars. ${ }^{3}$

Contrary to our current understanding of generic medications, biosimilars introduce a level of complexity that requires special considerations when being used as alternatives to the originator biologic. While the active ingredients of generics are expected to be identical to their respective branded products, given the complex nature of biosimilars and biologics manufacturing, creating a biosimilar that is identical to the innovator drug is not possible. Biosimilars are, therefore, similar or highly similar to the reference innovator products but are not exact replicas of them. In order to properly integrate biosimilars into patient care, pharmacists graduating in this era require a basic understanding of the underlying regulatory, scientific, and practice-related issues surrounding biologics and biosimilars.

The purpose of this article is to provide an initial framework by which pharmacy schools can incorporate biosimilars and related content into the didactic doctor of pharmacy (PharmD) curriculum. This paper reviews and recommends linking biosimilar regulatory, scientific, and practice-based concepts to educational and curricular outcomes. Recommendations regarding placement of specific concepts within multiple courses in the pharmacy 


\section{American Journal of Pharmaceutical Education 2017; 81 (3) Article 57.}

curriculum also are offered, as it is essential to incorporate different concepts related to biosimilars in a broad, interdisciplinary fashion to ensure proper integration in the existing curriculum.

\section{Relevance to Educational Outcomes}

The Accreditation Council for Pharmacy Education (ACPE) Accreditation Standards (ACPE Standards 2016) ${ }^{8}$ and the Center for the Advancement of Pharmacy Education (CAPE) Educational Outcomes (CAPE Outcomes 2013) ${ }^{9}$ are used within this manuscript as a starting point to guide biosimilar curricular discussions within schools of pharmacy. Individual PharmD programs should conduct their own review of the curricular content relevant to biosimilars, determine their relevance to the aforementioned ACPE Standards 2016 and CAPE Outcomes 2013, and ultimately map these to their own specific courses. In this manuscript, and for illustrative purposes only, the authors map the concepts of biosimilars to the ACPE Standards $2016^{8}$ and the CAPE Outcomes 2013. ${ }^{9}$ We intend not to be prescriptive, and expect readers to use this article as a guide or roadmap for implementing a biosimilar curriculum within their own PharmD curricula. A secondary objective for this article is to allow educators to assess gaps in the knowledge of students and practicing pharmacists and to develop specific curricular and continuing education programs to target these gaps.

The specific ACPE Standards Appendix 1 elements we have identified as relevant to biosimilars in the PharmD curriculum encompass the entire breadth of the pharmacy curriculum, and the key knowledge areas for biologics and biosimilars span all of the major domain areas: biomedical sciences, pharmaceutical sciences, social/administrative/behavioral sciences, and clinical sciences. These include: biochemistry, human physiology, immunology, pathophysiology, medicinal chemistry, biopharmaceutics, pharmacokinetics, pharmacology/pharmacodynamics, toxicology, ethics, health care systems, pharmacoeconomics, pharmacoepidemiology, pharmacy law and regulatory affairs, practice management, research design, health informatics, medication dispensing/distribution/administration systems, patient safety, and pharmacotherapy. ${ }^{8}$ Thus, integration of content by faculty will be imperative for successful implementation throughout the curriculum. For the CAPE Outcomes ${ }^{9}$ relevant to biologics and biosimilars, it is important to achieve foundational knowledge (Domain 1) from the biomedical sciences in order to apply concepts to patient-centered and populationbased care, managing medication-use systems (Domain 2), education, and interprofessional collaborations (Domain 3). Figure $1^{10,11}$ depicts an overview of how these concepts relate to each other and emphasizes the importance of providing an integrated approach toward including biosimilars within pharmacy curricula. Table $1^{8,9}$ combines all of these concepts, provides the map between biosimilar concepts and educational outcomes, and includes example learning objectives and in-class activities.

\section{Background on Biosimilars}

The Biologics Price Competition and Innovation Act of 2009 (BPCI Act) ${ }^{12}$ was passed to address rising drug and biologic expenditures, and allows for biologic agents to gain FDA approval by demonstrating similarity to already approved biologic products (biosimilars). A biosimilar is defined as a biological product that is highly similar to the reference product notwithstanding minor differences in clinically inactive components; and exhibits no clinically meaningful difference from the reference product in terms of the safety, purity, and potency of

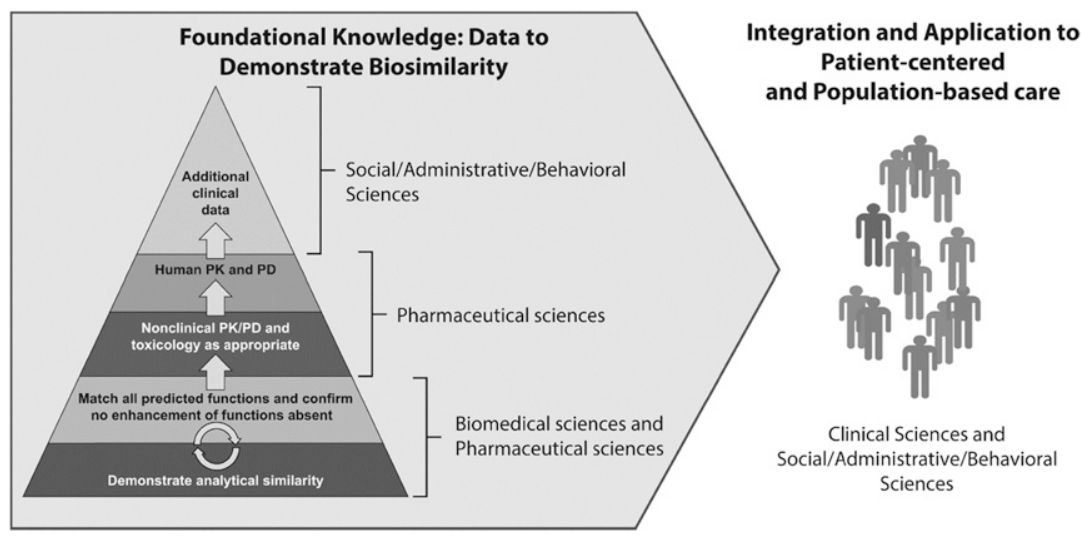

Figure 1. Foundational knowledge domains for demonstrating biosimilarity and application to patient-centered and populationbased care. Biosimilars should be incorporated into pharmacy curricula so that there is integration of these concepts across the various domains. Figure adapted from US Health and Human Services Food and Drug Administration guidelines. ${ }^{10,11}$ 
American Journal of Pharmaceutical Education 2017; 81 (3) Article 57.

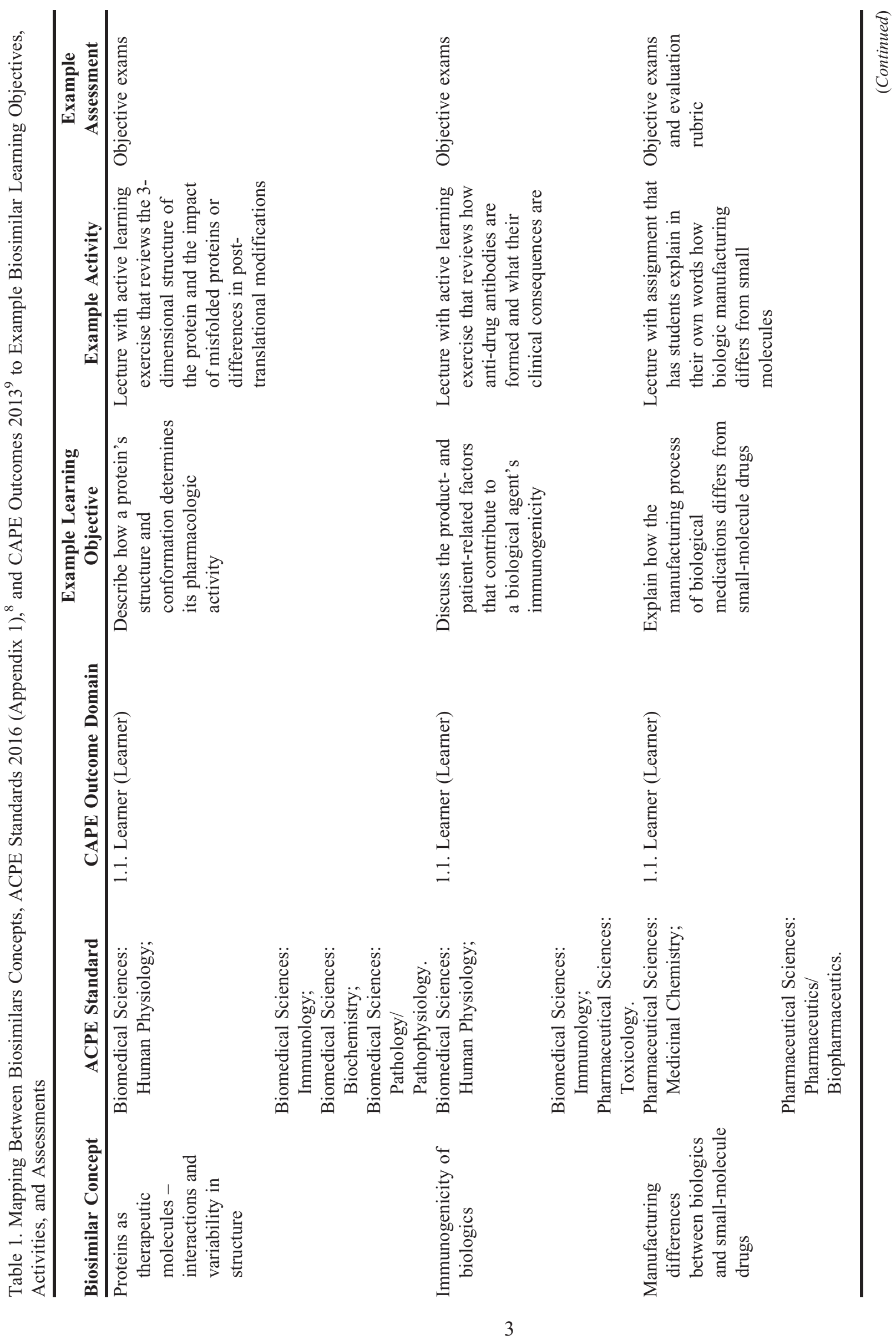


American Journal of Pharmaceutical Education 2017; 81 (3) Article 57.

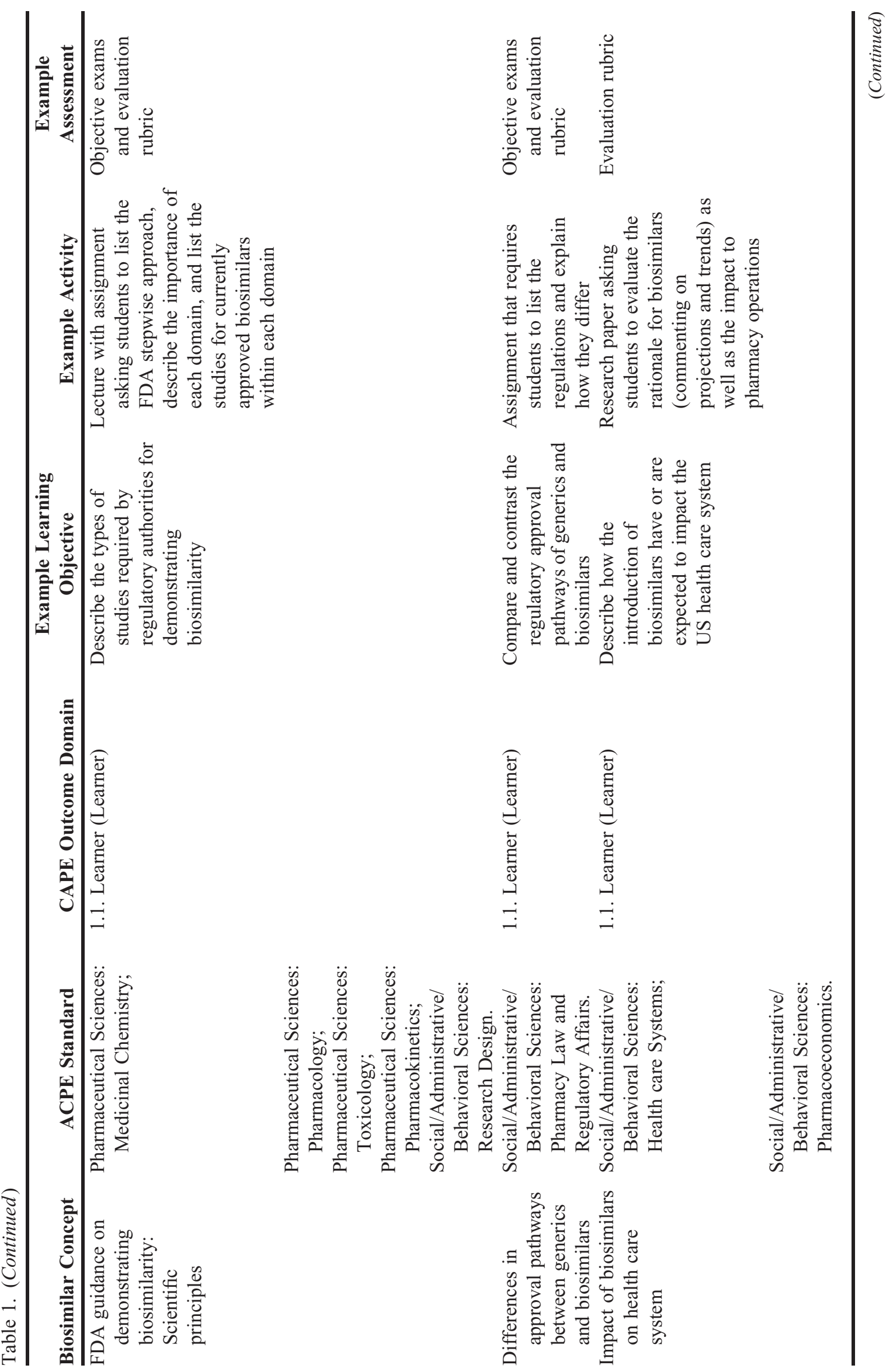


American Journal of Pharmaceutical Education 2017; 81 (3) Article 57.

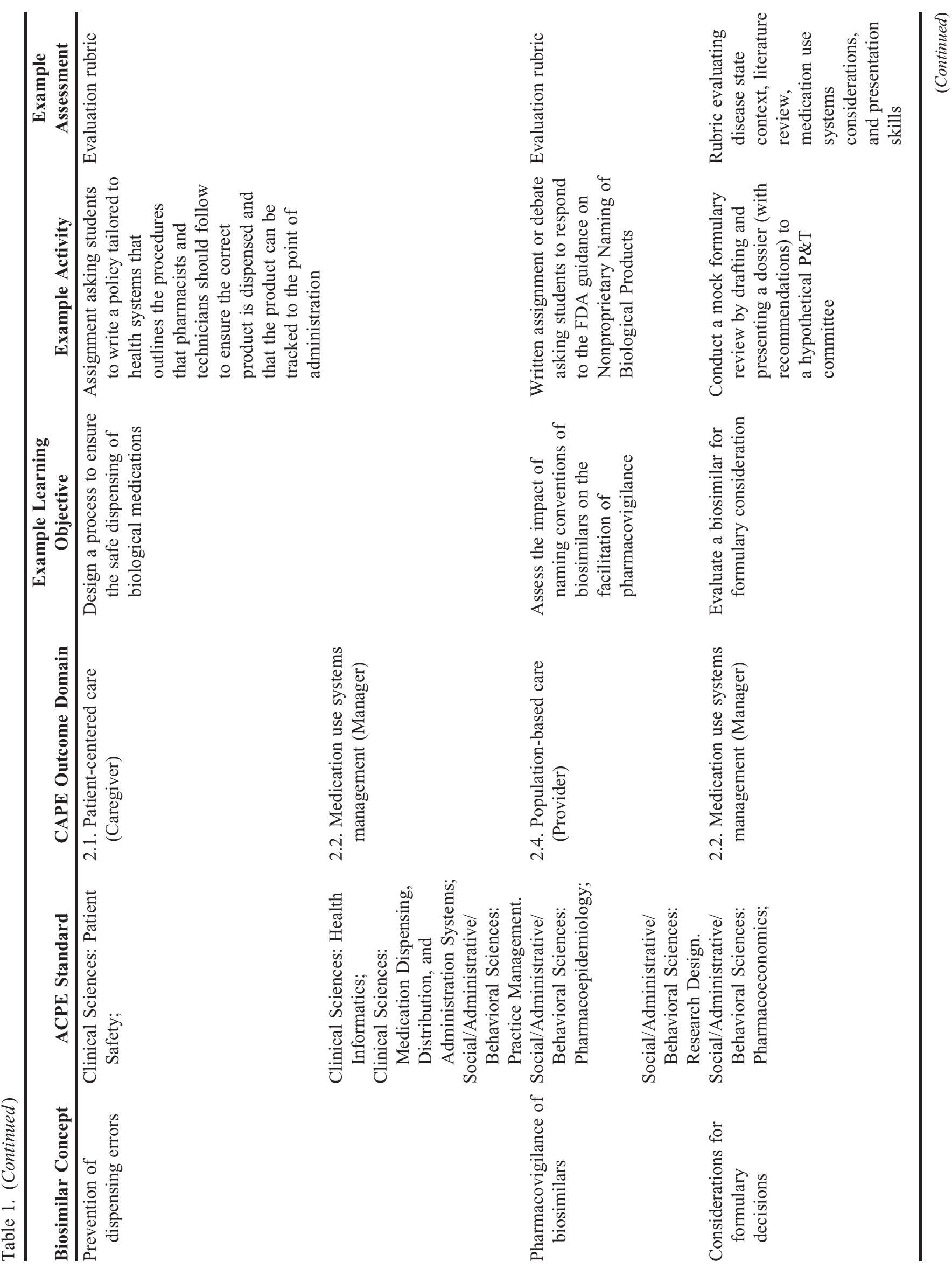


American Journal of Pharmaceutical Education 2017; 81 (3) Article 57.

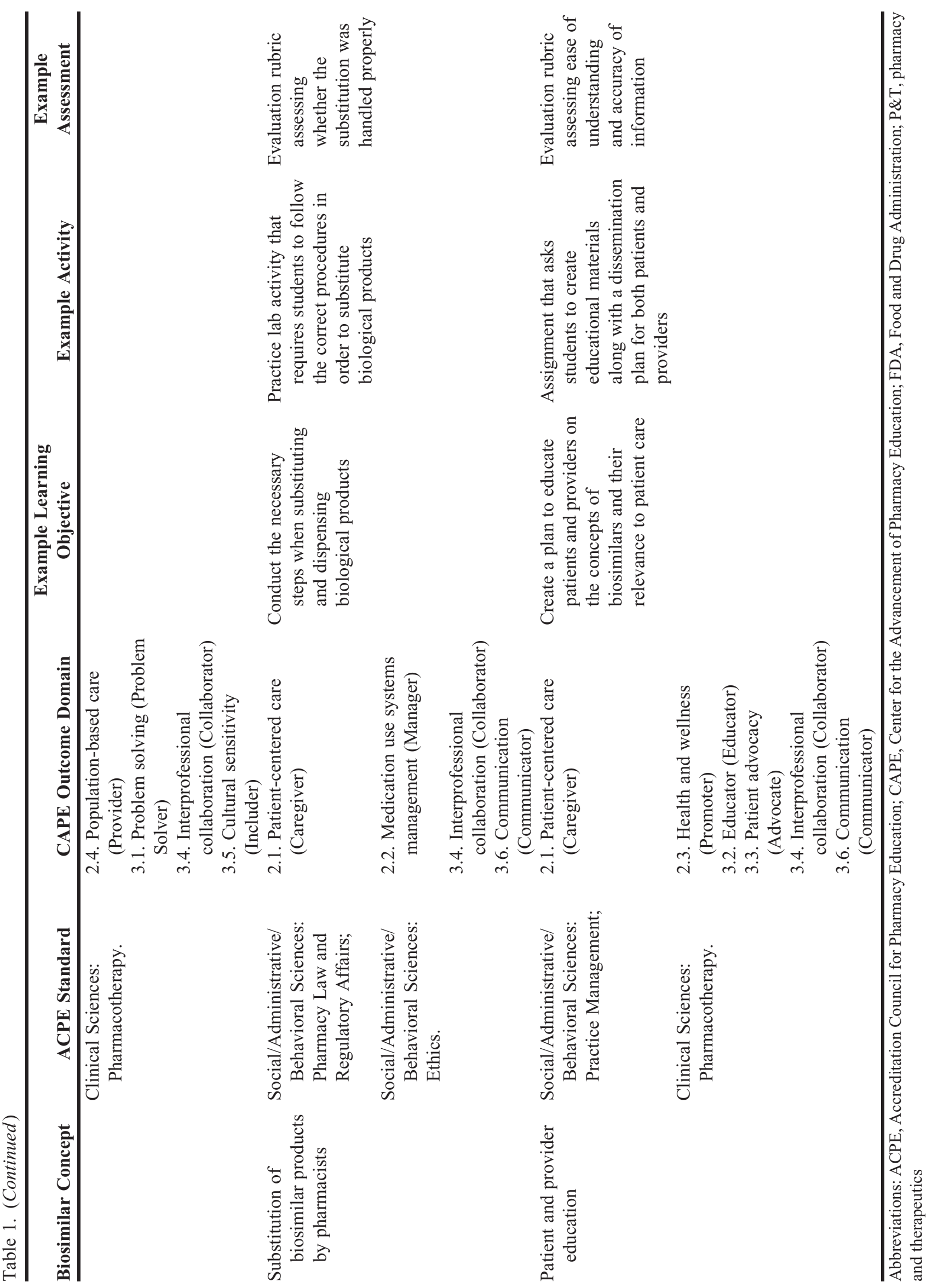




\section{American Journal of Pharmaceutical Education 2017; 81 (3) Article 57.}

the product (42 U.S.C. $\S 262(i)(2)) .{ }^{13}$ Once biosimilarity has been established, the BPCI Act also allows for an additional classification of "interchangeable" for a product that meets the specified safety standards and, therefore, may be substituted for the reference product without the intervention of the health care provider who prescribed the reference product (42 U.S.C. $\S 262(i)(3)) .^{13}$ The safety standards for interchangeability are described later in this manuscript. Because the law overseeing the development of biosimilars in the United States is relatively new, colleges and schools of pharmacy may not have formally incorporated these concepts into their curricula. The successful adoption and utilization of biosimilars into clinical practice is contingent upon the practitioner's knowledge and understanding of the concept. An educational needs assessment ${ }^{14}$ of more than 200 practicing clinicians (including more than 50 pharmacists) in the United States indicated that while there is a significant interest in utilizing biosimilars in practice, there were clear knowledge gaps regarding the definition of biosimilars and their regulatory approval process. Almost all respondents $(97 \%)$ indicated the need for more education related to biosimilars. ${ }^{14}$

Considering the changing landscape of pharmaceutical products, being "practice-ready" should be a basic competency within the key knowledge domains of biosimilars because PharmD graduates who act as managers of the medication use process will face significant challenges incorporating biologics and biosimilars in their practices. These challenges include the domains of formulary analysis, order management and information systems, inventory management, financial analysis, and patient/provider education. ${ }^{15}$ Accordingly, contemporary pharmacists will require in-depth knowledge regarding scientific principles of biologics and biosimilars, as well as the clinical, operational, and regulatory application of these products. Thus, based on these considerations, we have developed the following knowledge domains that we recommend be incorporated into the PharmD curriculum: the legal definitions of biologics, biosimilars, and interchangeable biosimilars; biosimilar development and regulation; state pharmacy practice laws as applied to biologics; and pharmacy practice management with biologics.

\section{Key Educational Parameters What Is a Biologic Product?}

Level: Beginner; place in curriculum: Early, within the first year; links to other content areas: Pharmacovigilance (Pharmacy Practice Management Issues)

Within the early portion of the PharmD curriculum, students should understand the definition of a biologic product as provided in the Public Health Service Act (42 U.S.C. § 262(i)(1)). ${ }^{13}$ Students should further understand that biologics are therapeutic molecules derived from living organisms, and they differ from small-molecule drugs in multiple aspects, including structural complexity (complex protein folding vs. simple chemical structure), and manufacturing techniques (bioprocessing technology vs. synthetic chemistry). ${ }^{16,17}$ They should understand that such complexities result in heterogeneity not seen in small-molecule drugs because of various factors, including differences in protein sequences, folding, disulfide bond formation, post-translational modifications, process impurities, ${ }^{16}$ and degredation. ${ }^{18}$ The consequences of these types of chemical or physical modifications could range from loss of efficacy to increased safety concerns. ${ }^{17}$

These foundational concepts can facilitate understanding of a key safety concern with biologics: immunogenicity. PharmD graduates should understand that all biologics carry varying risks of immunogenicity, which can be influenced by product-related factors (eg, structural properties, manufacturing processes and storage, purity, and contamination) and patient-related factors (eg, genetic predisposition to produce neutralizing antibodies, expression of the endogenous equivalent of the product, and comorbid conditions). The PharmD graduate should be able to distinguish that the consequences of immunogenicity can vary from clinically irrelevant to potentially lethal. ${ }^{18}$ Immunogenic effects are unpredictable and difficult to measure accurately (and consistently). Clinical evaluation of safety and efficacy data, including post-marketing pharmacovigilance, will be important to detect uncommon but serious adverse events. ${ }^{19}$ Understanding these concepts will reinforce to the PharmD graduate the importance of establishing pharmacovigilance processes to go along with the medication use processes at their institutions and practices.

Concepts related to the definition, characteristics, and safety of biologics can be presented during didactic lectures with active learning exercises reviewing key components. This can be assessed using objective exams (Table $1^{8,9}$ ).

\section{How Are Biosimilars Developed and Regulated?}

Level: Intermediate; place in curriculum: during the first two years of a traditional 4-year program; links to other content areas: State Pharmacy Practice Laws

The biosimilar approval pathway provides a legal mechanism for the development of "similar biologics" that is expected to save development time and resources. ${ }^{16}$ For this reason, studies in support of a biosimilar application are focused on establishing analytical, 


\section{American Journal of Pharmaceutical Education 2017; 81 (3) Article 57.}

functional, and clinical similarity to the reference product rather than duplicating efficacy and safety testing. ${ }^{16}$ An understanding of the robust similarity studies required for biosimilars to be approved by the FDA can provide PharmD graduates with an appreciation of the complexity of biosimilar development and the expertise and experience required for their development.

The process starts with understanding critical quality attributes of the innovator product to evaluate its structural and functional characteristics. Based on this knowledge, the design and development of the biosimilar drug substance and drug product is then undertaken. The required testing involves comparative analytical and functional characterization (structural and functional studies to characterize molecular weight, structure, post-translational modifications, heterogeneity, biological activities, purity, and stability) to match critical quality attributes and ensure high similarity between the proposed biosimilar and reference product. The comprehensive analytical similarity assessments serve as the foundation for biosimilar development as well as the basis for the design of subsequent preclinical or clinical studies. ${ }^{11}$ Additional studies may include comparative pharmacokinetic, pharmacodynamic, clinical efficacy, clinical safety, and immunogenicity studies to further demonstrate biosimilarity. ${ }^{20}$ Generally, the final step is a confirmatory clinical study performed in a sensitive population using sensitive endpoints to resolve any residual uncertainties (Figure 1). ${ }^{11}$ The FDA has published guidance documents with details on the appropriate methods for these analytical, preclinical, and clinical tests. $10,11,20$

Data in support of approval of a biosimilar are expected to include direct comparisons with the innovator reference biologic. A biosimilar application also may include data and information to support extrapolation to indications of the reference biologic that have not been clinically tested by the biosimilar manufacturer. Extrapolation depends on various factors including scientific justification based on mechanism of action and similar bioavailability and safety in different patient populations. The decision to grant extrapolation is made on a case-bycase basis by the regulatory agency. ${ }^{16}$ A concept paper on extrapolation describes a framework that includes patient, disease, and endpoint factors that should be considered by regulatory authorities to decide whether to allow extrapolation of biosimilarity across populations or indications not evaluated clinically. ${ }^{21}$ PharmD graduates should be able to understand what extrapolation means to develop the ability to make treatment decisions to the extent permitted under state law and in their role on formulary committees. ${ }^{22}$
Once biosimilarity is established, an "interchangeable" designation can be obtained from the FDA if the biosimilar manufacturer demonstrates: similar clinical results to the reference product in any given patient; and no additional safety risks or diminished efficacy when switching between the biosimilar and the reference product compared with the reference product alone (42 U.S.C. $\S 262(\mathrm{i})(3) .{ }^{13}$ It is important for pharmacists to understand that depending on state law, an interchangeable biosimilar may be appropriately substituted by a pharmacist without contacting the prescriber for authorization. ${ }^{12}$ As of July 2016, 25 states plus Puerto Rico have adopted laws that address substitution of interchangeable biosimilars. ${ }^{23}$ The FDA has released in January 2017, draft industry guidelines on the type of information required for establishing interchangeability.

Another important consideration after approval is post-marketing pharmacovigilance. The FDA guidance on the Scientific Considerations in Demonstrating Biosimilarity to a Reference Product ${ }^{24}$ states that post-marketing surveillance or studies may be needed to evaluate safety risks in some cases, which would need to take into consideration any particular safety or effectiveness concerns associated with the reference product and its class, the proposed biosimilar product, and the patient population. The proposed monitoring programs should be able to differentiate between adverse events associated with the reference product and the proposed biosimilar, and identify adverse events associated with the proposed biosimilar that were not previously associated with the reference product. These considerations are particularly important for rare, but serious adverse events that may not be detected in pre-approval clinical testing. ${ }^{24}$ Post-marketing surveillance also can be used to verify that no clinical consequences arise as a result of switching between interchangeable biosimilars and their respective reference biologics.

Future pharmacists should also be aware of the controversy surrounding issues related to interchangeability, distinctive nonproprietary names, and pharmacovigilance for biosimilar products. ${ }^{25}$ Arguments made in favor of naming policies that account for the differences between generic drugs and biosimilars are grounded in the scientific differences between chemically synthesized drugs and biological products, and include the need for robust pharmacovigilance of all biological products, complete and accurate patient records, and precise attribution of adverse events to the appropriate product. Arguments made in favor of policies that minimize such distinctions include concerns over the potential for patient and prescriber confusion, complications with existing dispensing software, the potential for reduced utilization of 


\section{American Journal of Pharmaceutical Education 2017; 81 (3) Article 57.}

biosimilars, and increasing health care costs. ${ }^{26}$ In 2015 , the FDA released a draft guidance on "Nonproprietary Naming of Biological Products," ${ }^{27}$ which shares some similarities with the "Biological Qualifier" scheme proposed by the World Health Organization (WHO) earlier in $2015 .{ }^{28}$ As policies at the WHO and FDA level evolve and become finalized, it will be necessary for graduating pharmacists to be aware of naming considerations as they implement pharmacy dispensing and substitution laws to better inform their practices.

Concepts related to the regulation, development, data extrapolation, interchangeability, and naming of biosimilars can be presented during didactic lectures and assessed using objective exams. Active learning exercises could utilize case study reviews of approved biosimilars in which students match the data to the regulatory requirements. Debates surrounding the guidances in draft form by the FDA would reinforce the complex issues of naming, interchangeability, and pharmacovigilance. This can be assessed using objective exams and evaluation rubrics for active learning exercises (Table $1^{8,9}$ ).

\section{State Pharmacy Practice Laws}

Level: Intermediate; place in curriculum: in context with medication dispensing, distribution, and administration; links to other content areas: Pharmacy Practice Management Issues

PharmD graduates should be aware of the differences between federal and state laws regarding biosimilars and how they will impact their practices. The purpose for allowing pharmacist substitution/selection of the biologic product to be dispensed is to broaden product selection and thus further competition while maintaining the same efficacy and safety profile to achieve patient treatment goals. ${ }^{16,29}$ The overarching framework for substitution of biosimilars at the pharmacy level should have appropriate differences to account for the distinction between drugs and biologics and especially biosimilars. ${ }^{16,30}$ Product selection criteria should be tied to the FDA interchangeability designation, although state laws may or may not take this into account. ${ }^{16}$ Accordingly, pharmacy schools will need to incorporate specific state laws and regulations into their own curricula, including whether or not prescribers have the option to specify the product to be dispensed (eg, "dispense as written" authority); if patients and prescribers should be notified of the specific biological dispensed; and how long records of the substitution should be maintained. These considerations apply mainly to the community setting, and graduating pharmacists should be aware if exemptions are made for institutions and health systems with formulary processes (eg, pharmacy and therapeutics committees). ${ }^{16}$
The knowledge that each biosimilar is unique is foundational to understanding biosimilar substitution. It is important to understand that each biosimilar is developed based on comparisons with the reference innovator product, but there are no requirements to conduct comparative studies between two approved biosimilars. Accordingly, this will likely mean that while the pharmacist may be able to substitute an interchangeable biosimilar for the reference product (and vice-versa), it would likely not be appropriate for the pharmacist to substitute one biosimilar product for another. For example, if two biosimilars (A and B) were approved for a reference biologic and both gained the interchangeable designation from the FDA, pharmacists may be able to use both of them as substitutes for the reference product. If, however, a patient had been receiving Biosimilar A, the pharmacist may not be able to dispense Biosimilar B and may be required to dispense either the reference product or Biosimilar A. The specifics of this process will depend on how state pharmacy laws evolve. This concept varies greatly from the current paradigm for substituting generic medications, in which most generic products of the same molecule may be appropriately substituted for each other without concern for differences in safety or efficacy.

In addition to presenting relevant state practice laws during didactic lectures, lab-based activities should be developed to ensure that students follow the proper procedures for biologic substitution, in accordance with specific state pharmacy practice laws. These activities can be assessed using evaluation rubrics (Table $1^{8,9}$ ).

\section{Pharmacy Practice Management Issues}

Level: Advanced; place in curriculum: in context with clinical therapeutics courses; links to other content areas: integrates all previously discussed concepts

Institutions must determine the appropriate use of biosimilars within their scope of practice, a task with which future pharmacists would be expected to be involved. PharmD students should be able to analyze biosimilars with respect to considerations of comparative data for formulary considerations, product indications, pharmacovigilance plans, business considerations (including staff time, profit margin, and effect on patients), reliability of supply, and treatment guidelines that may include policies on therapeutic interchangability. ${ }^{15}$ Appropriate product naming and labeling should be established to facilitate distinction between manufacturers, especially if both a biosimilar and its reference product will be stocked. Order sets, protocols, medication records, medication reconciliation processes, and pharmacy purchasing processes will need to be updated. PharmD graduates also will need to educate health care providers and patients. ${ }^{15}$ 


\section{American Journal of Pharmaceutical Education 2017; 81 (3) Article 57.}

The impact of biosimilars on health care systems can be introduced using assignments that require students to evaluate the rationale and impact of biosimilars and require them to write policies aimed at reducing medication errors. Students should prepare comprehensive summaries for an FDA-approved biosimilar and participate in a mock pharmacy and therapeutics committee review for formulary consideration. This can be assessed using evaluation rubrics (Table $1^{8,9}$ ).

\section{CONCLUSIONS}

Within this manuscript, we have provided an overview of key educational concepts regarding biosimilars and how they relate to modern pharmacy educational outcomes. For inclusion in specific curricula, faculty will need to discuss where in their own curricula the aforementioned knowledge areas require introduction, reinforcement, and application.

The approval of biosimilar and interchangeable biologics is expected to have an effect on health care in terms of expenditures, patient access to medication, and state regulations for substitution by pharmacists. It will be important to utilize biosimilars to maximize costeffectiveness, while simultaneously prioritizing patient safety. It would serve pharmacists well to understand the complexity of biosimilar development, how these products differ from small-molecule generics, and the importance of the expertise required to develop biosimilars to appropriately identify the place of these products in the treatment paradigm and, thus, ensure optimal patient care. With this education, pharmacists will be able to provide leadership in balancing financial considerations with clinical safety and efficacy considerations in both the pharmacy and therapeutics formulary decision process as well as in the community setting. Ensuring that graduating pharmacists are equipped with the necessary knowledge to manage daily responsibilities with regard to biologics and biosimilars will contribute toward ensuring the appropriate use of these new agents.

\section{ACKNOWLEDGMENTS}

Funding to support for the preparation of this manuscript was provided by Amgen Inc. to MedVal Scientific Information Services, LLC, Skillman, NJ. The authors thank Rozena Varghese, RPh, PharmD, of MedVal for providing medical writing and editorial assistance. The authors provided a detailed outline and key references to the writer, who created the first manuscript draft under direction of the authors. All authors participated in multiple revisions of the manuscript, which were incorporated by the writer. All authors reviewed the final manuscript and gave approval for submission. It should be noted that Ed Li is a consultant for Eli Lilly, Hospira, and Pfizer. He also is a speaker for Pfizer. Jennifer Liu is an Amgen employee and stockholder, as is Monica Ramchandani.

\section{REFERENCES}

1. US Centers for Medicare \& Medicaid Services. National health expenditures 2015 highlights. http://www.cms.gov/ResearchStatistics-Data-and-Systems/Statistics-Trends-and-Reports/ NationalHealthExpendData/Downloads/highlights.pdf. Accessed April 20, 2017.

2. US Centers for Medicare \& Medicaid Services. National health expenditure projections 2015-2025. https://www.cms.gov/ResearchStatistics-Data-and-Systems/Statistics-Trends-and-Reports/ NationalHealthExpendData/Downloads/Proj2015.pdf. Accessed March 6, 2015.

3. Zellmer WA. Pharmacy forecast 2016-2020: strategic planning advice for pharmacy departments in hospitals and health systems. Bethesda, MD: ASHP Research and Education Foundation; 2015. 4. US Food and Drug Administration. FDA approves first biosimilar product Zarxio. http://www.fda.gov/NewsEvents/Newsroom/ PressAnnouncements/ucm436648.htm. Accessed November 28, 2016.

5. US Food and Drug Administration. FDA approves Inflectra, a biosimilar to Remicade. http://www.fda.gov/NewsEvents/ Newsroom/PressAnnouncements/ucm494227.htm. Accessed November 28, 2016.

6. US Food and Drug Administration. FDA approves Erelzi, a biosimilar to Enbrel. http://www.fda.gov/NewsEvents/Newsroom/ PressAnnouncements/ucm518639.htm. Accessed November 28, 2016.

7. US Food and Drug Administration. FDA approves Amjevita, a biosimilar to Humira. http://www.fda.gov/NewsEvents/Newsroom/ PressAnnouncements/ucm522243.htm. Accessed November 28, 2016.

8. Accreditation Council for Pharmacy Education. Accreditation standards and key elements for the professional program in pharmacy leading to the doctor of pharmacy degree. https://www.acpe-accredit. org/pdf/Standards2016FINAL.pdf. Standards 2016. Accessed November 28, 2016.

9. Medina MS, Plaza CM, Stowe CD, et al. Center for the Advancement of Pharmacy Education 2013 educational outcomes. Am J Pharm Educ. 2013;77(8):Article 162.

10. US Department of Health and Human Services. Scientific considerations in demonstrating biosimilarity to a reference product. Guidance for industry. http://www.fda.gov/downloads/Drugs/ GuidanceComplianceRegulatoryInformation/Guidances/ UCM291128.pdf. Accessed November 28, 2016.

11. US Department of Health and Human Services, Food and Drug Administration, Center for Drug Evaluation and Research, Center for Biologics Evaluation and Research. Guidance for industry: clinical pharmacology data to support a demonstration of biosimilarity to a reference product. http://www.fda.gov/downloads/Drugs/ GuidanceComplianceRegulatoryInformation/Guidances/ UCM397017.pdf. Accessed November 28, 2016.

12. US 111th Congress (2009-2010). Biologics Price Competition and Innovation Act of 2009. Title VII, Subtitle A of the Patient Protection and Affordable Care Act (HR 3590). http://www.fda.gov/ downloads/Drugs/GuidanceComplianceRegulatoryInformation/ UCM216146.pdf. Accessed November 28, 2016. 


\section{American Journal of Pharmaceutical Education 2017; 81 (3) Article 57.}

13. Office of the Law Revision Council. Regulation of Biological Products, 42 USC \$262. http://uscode.house.gov/view.xhtml?req= granuleid:USC-prelim-title42-section262\&num $=0 \&$ edition $=$ prelim . Accessed November 28, 2016.

14. Exploring the future of biological therapy and the role of biosimilars. http://www.biosimilarscme.org/content/Biosimilars_ whitepaper.pdf. Accessed November 28, 2016.

15. Lucio SD, Stevenson JG, Hoffman JM. Biosimilars: implications for health-system pharmacists. Am J Health Syst Pharm. 2013;70 (22):2004-2017.

16. Zelenetz AD, Ahmed I, Braud EL, et al. NCCN biosimilars white paper: regulatory, scientific, and patient safety perspectives. $J$ Natl Compr Cancer Network. 2011;9(suppl 4):S1-S22.

17. Abraham I, Sun D, Bagalagel A, et al. Biosimilars in 3D:

definition, development and differentiation. Bioengineered. 2013;4

(4):203-206.

18. Kuhlmann M, Covic A. The protein science of biosimilars. Nephrol Dial Transplant. 2006;21(suppl 5):v4-v8.

19. Crommelin D, Bermejo T, Bissig M, et al. Pharmaceutical evaluation of biosimilars: important differences from generic low-molecular-weight pharmaceuticals. Eur J Hosp Pharm Sci. 2005;11(1):11-17.

20. US Food and Drug Administration. Bioanalytical method validation. Rockville, MD: US Department of Health and Human Services; 2001.

21. European Medicines Agency. Concept paper on extrapolation of efficacy and safety in medicine development. http://www.ema.

europa.eu/docs/en_GB/document_library/Scientific_guideline/2013/ 04/WC500142358.pdf. Accessed November 28, 2016.

22. Weise M, Kurki P, Wolff-Holz E, Bielsky MC, Schneider CK. Biosimilars: the science of extrapolation. Blood. 2014;124(22):31913196.
23. Morley JS. New perspectives in our use of opioids. Pain Forum. 1999;8(4):200-205.

24. US Department of Health and Human Services, Food and Drug Administration, Center for Drug Evaluation and Research, Center for Biologics Evaluation and Research. Scientific considerations in demonstrating biosimilarity to a reference product. Guidance for industry. http://www.fda.gov/downloads/Drugs/

GuidanceComplianceRegulatoryInformation/Guidances/ UCM291128.pdf. Accessed November 28, 2016.

25. Traynor K. Stakeholders discuss biosimilar naming, substitution. Am J Health Syst Pharm. 2014;71(6):446-447.

26. Academy of Managed Care Pharmacy, American Pharmacists Association, America's Health Insurance Plans, et al. Biosimilars council, pharmacies, payers, and others letter to FDA regarding biosimilar names. http://www.gphaonline.org/media/cms/BSN_Letter_ on_Biosimilars_Naming_June2015_FINAL_2.pdf. Accessed November $28,2016$.

27. US Department of Health and Human Services. Nonproprietary naming of biological products. Guidance for industry [draft guidance]. http://www.fda.gov/downloads/Drugs/ GuidanceComplianceRegulatoryInformation/Guidances/ UCM459987.pdf. Accessed November 28, 2016.

28. World Health Organization. Proposal for assignment of biological qualifiers (BQ). http://www.who.int/medicines/services/ inn/bq_innproposal201407.pdf. Accessed November 28, 2016. 29. Tyler LS, Cole SW, May JR, et al. ASHP guidelines on the pharmacy and therapeutics committee and the formulary system. Am J Health Sys Pharm. 2008;65(13):1272-1283.

30. Li E, Ramanan S, Green L. Pharmacist substitution of biological products: issues and considerations. J Manag Care Spec Pharm. 2015;21(7):532-539. 